\title{
Memoricídio das populações negras no Brasil: atuação das políticas coloniais do esquecimento
}

\section{Memoricide of Black populations in Brazil: performance of colonial policies of oblivion}

Enviado em: 30/09/2020

Aceito em: 05/01/2021

Leandro Aparecido Fonseca Missiatto $^{1}$

\section{Resumo}

Impor o esquecimento às memórias de dor e resistência das populações negras é uma prática recorrente neste país. Nas artes, ciências, religiões, espaços públicos e outros territórios de expressão do ser, a presença negra é constantemente apagada pela mão invisível da colonialidade, que impõe o esquecimento das experiências de dor, prazer e resistência de ser negro e negra no Brasil. Este ensaio discute o assassinato das memórias afro-brasileiras como uma política do esquecimento orquestrada pela colonialidade que permanentemente nos exaure. Discute ainda a resistência que não queda aos poderes imperialistas de interdição ao saber, ser e poder das identidades subalterizadas que, pela consciência ativa de seu lugar de fala, vêm produzindo novas possibilidades de diálogo com os poderes hegemônicos.

Palavras-chave: Memoricídio; Políticas do Esquecimento; Resistência.

\begin{abstract}
Imposing forgetfulness on the memories of pain and resistance of Black populations is a recurring practice in this country. In the arts, sciences, religions, public spaces and other territories of expression of being, the Black presence is constantly erased by the invisible hand of coloniality that imposes forgetting the experiences of pain, pleasure and resistance of being Black and black in Brazil. This essay discusses the murder of Afro-Brazilian memories as a policy of oblivion orchestrated by coloniality that hás permanently exhausted us. It also discusses the resistance that does not fall to the imperialist powers of interdiction to the knowledge, being and Power of under valued indentities that, due to the active awareness of their place of speech, have been producing new possibilities of dialogue with the hegemonic powers.
\end{abstract}

Keywords: Memoricide; Forgetfulness Policies; Resistance.

1 - Possui Mestrado em Psicologia na Universidade Federal de Rondônia - UNIR, Linha de Pesquisa em Saúde e Processos Psicossociais.Graduação em psicologia pela Faculdade de Ciências Biomédicas de Cacoal (2012). Vice-líder do LARIS, Laboratório de Relações Interpessoais e Saúde do Departamento de Psicologia da Universidade Federal de Rondônia (UNIR). Atualmente é analista processual na especialidade de psicologia - Tribunal de Justiça do Estado de Rondônia.. 


\section{Introdução}

Neste país se cresce ouvindo histórias referentes ao sobrenome, estas não dizem respeito à identificação de pessoas negras, são histórias brancas. Toda pessoa branca orgulha-se em falar de sua ancestralidade, de sua origem italiana, polonesa, espanhola, portuguesa, alemã etc. Pelo sobrenome muitos alcançam o direito à dupla cidadania, resguardam prestígios e acessam histórias anteriores ao próprio nascimento. Mas, as pessoas de pele negra não. Suas histórias, são fragmentos e suas ancestralidades estão encobertas pelo denso véu da colonialidade escravagista. Não se sabe de que lugar de África vieram, a qual reino pertenciam, quais foram as principais lutas de seus ancestrais, como seu povo se organizou e construiu sua política milenar. Não se sabe qual o prato típico de seu país de origem, as danças que se dançavam e as músicas entoadas para o ninar de seus filhos noites após noite, séculos a dentro. Não se sabe ainda qual homem ou qual mulher de sua linhagem foi o primeiro ou a primeira a tocar seus pés nesse país. Desse modo, enquanto a pessoa branca sabe, nós, pretas e pretos do Brasil, não sabemos. E não sabemos pelas imposições da colonização, pela força aniquilante da escravidão que reduziu a negritude a uma subcategoria humana que, sem acesso à história original, tomou para si mesma apenas os relatos da desonrosa posição existencial determinada pela coloração das epidermes.

Aqueles nascidos na outra margem da humanidade, do outro lado da diferença colonial, da diferença ontológica, que se encontram separados pelo fosso do Não Ser que flui da branquitude colonial e os enuncia como inferiores, têm histórias e essas histórias importam e devem ser contadas, mas não pelos sujeitos hegemônicos, pois estes fizeram dessas narrativas algo menor, sem prestígio, tão vergonhoso a ponto de serem recusadas pela própria negritude. A branquitude que enunciou as identidades ameríndias e africanas enquanto sujeitos menores dentro do continnumhumano lançou os saberes e discurso da ancestralidade negra aos domínios do silêncio e do silêncio aos recônditos do esquecimento. Desse modo, o esquecimento dos saberes e memórias do povo negro não resulta de processos naturais da história humana em que partes se perdem no tempo que a tudo corrói, pelo contrário, é fruto de ações intencionais executadas pelas elites coloniais que, desde o princípio da formação desse país, agem de inúmeros modos para coibir o direito de Ser e estar das pessoas afrodescendentes na geografia dos saberes e dos territórios. Impetrado por órgãos e representantes do Estado a imposição da morte das memórias negras a partir do 
banimento da presença dessas pessoas na arte, filosofia, cultura, política, ciência e espaços urbanos é, não por outras razões, mas pelo próprio intento de extermínio das diferenças inferiorizadas, políticas do esquecimento (POLLAK, 1989).

Contudo, embora seja de longa data a ação das forças de invisibilização dos saberes afrodescendentes, o povo negro é sempre insurgência a reivindicar espaços e a produzir respostas criativas a essas questões, não permitindo o êxito dos projetos coloniais que buscam desenraizar a presença negra da história nacional. As vozes que se levantam contra os apagamentos determinados por grupos hegemônicos partem das vivências da negritude e desvelam o que ficou oculto pela diferença colonial que globalizou a única história contada pelos colonizadores e que pôs sob os escombros dessas narrativas preeminentes as diversas percepções nascidas da experiência do contato colonial. Sendo assim, os diálogos da resistência negra emanam do lugar de fala dos subalternos, de suas realidades e são as chaves para superação da fratura enunciativa produzida pela diferença colonial.

Para avançar nas discussões sobre as políticas do esquecimento e a execução do memoricídio negro, este artigo busca discutir esse assunto sob as lentes das teorias decoloniais e da resistência negra, manifesta pela recusa ao silenciamento que, seja de modo individualizado ou organizado, não queda aos ditames coloniais que se encontram em vigor.

\section{Memoricídio da negritude brasileira: políticas coloniais do esquecimento}

Que histórias habitam do outro lado do Atlântico, em África? Como será que um menino é enunciado em sua vida escolar naquele continente ancestral? Como os familiares se referem ao cabelo, nariz ou aos lábios fartos de seus descendentes? Quais músicas esses ancestrais cantavam para seus filhos quando eles não passavam de apenas uma promessa de humano? Essas coisas eu não sei, conheço apenas o outro lado, contido nos limites dos navios negreiros, do cárcere e da desonra. Sei que no Brasil um menino negro em idade escolar é uma criança preta, por vezes pobre, chamado de moreninho, pretinho, buiu, macaco etc. Aqui o cabelo crespo é ruim e o nariz e lábios grossos são feios. Que quando ainda se é apenas um bebê se é assombrado com a cantiga de um "boi da cara preta" que pega os meninos. Aqui, sabe-se, desde muito pequeno, que a beleza, nobreza, justiça e honra não foram reservadas para anegritude e que para alcançar, por menor que seja, esses valores é preciso passar pelo escrutínio da branquitude que exigirá, em últimas instâncias, que a 
pessoa negra afaste-se de sua ancestralidade, buscando vir a ser uma pessoa branca que, obviamente, nunca conseguirá (FANON, 2008).

O apagamento dessas histórias ancestrais é complexo, não sendo tarefa fácil mapear as muitas estratégias que vêm sendo, ao longo dos séculos, usadas pelos grupos hegemônicos para deportar ao desaparecimento os símbolos e saberes do povo negro. Todavia, é certo que esses processos, independenteda capilaridade, possuem em comum o período colonial como origem. Certo também é que em épocas de escravidão o apagamento das identidades e cultura negra começava pela destituição do nome africano. Assim, quando uma pessoa negra chegava ao Brasil era despida de seu nome e batizada com um único nome de origem cristã, sem direito a sobrenome (PALMA; TRUZZI, 2018). Logo, o início da vida de um escravo ou escrava vindo da África se dava inicialmente pela ruptura identitária. A pessoa negra que se reconhecia enquanto um Ser transpessoal, identificado e identificante a partir dos inúmeros elementos ancestrais da sua terra, via-se como um alguém despersonificado, fragmentado em sua origem, um alguém que refletia o Outro (colonizador), e não mais a si mesmo. Assim, a negação do nome enquanto funcionava para o colonizador como uma estratégia nominativa de objetificação das vidas negras, implicava à pessoa escravizada na desorganização de si, no enfraquecimento de sua potencia ancestral e na obstrução dos sentidos seculares de Ser pessoa.

Com o passar do tempo, à medida que sedimentam o preconceito e a inferioridade da negritude, não apenas a cor da pele serve como justificativa para se desprezar, mas toda e qualquer herança que possa associar a pessoa à ancestralidade negra, incluindo aí o sobrenome, o que fazia com que muitas pessoas escravizadas que mantiveram o nome de origem, fosse pela vergonha ou pelo medo, aos poucos convertessem seus sobrenomes de nascimento para os de origem europeia (SILVA, 2017).Com isso não se perdia apenas um nome e sobrenome, com eles iam embora também as heranças, as raízes da árvore da vida, as histórias acerca da instituição do nome, enfim, as memórias familiares e coletivas que eles abarcavam, bem como a possibilidade de reconhecimento como parte fundamental de alguma coisa superior a si mesmos. Perder o nome e sobrenome significava, desse modo, cortar o caule da árvore existencial, determinando às vidas rompidas, uma morte lenta, desnutrida e seca. Era o mesmo que retirar o Ser dos perímetros da humanidade, haja vista que sucumbindo sua cultura, suas histórias, suas crenças, seus processos 
afirmativos de tornar-se pessoa, o que restava era apenas um espectro fantasmagórico da pessoa que um dia foram(DU BOIS, 1999).

Após o estrangulamento das primeiras histórias dos sujeitos com 0 aniquilamento de seus nomes, o que ocorria a partir daí era uma sequência de anulamentos que iam literalmente apagando da história individual e coletiva as marcas ancestrais das trajetórias dos povos africanos nas Américas. Conforme Walter Mignolo,a determinação do colapso dessas histórias diz respeito ao que ele chamou de diferença colonial, espaço conflitivo em que histórias locais são soterradas pelas imposições daquelas que se fizeram universais (MIGNOLO, 2003). O conceito proposto pelo filósofo argentino dá especial atenção às narrativas que se tornaram hegemônicas ao passo que outras, por meio da força colonial, foram tratadas como inferiores. Esse processo determinou quais histórias mereciam ser contadas ao mesmo tempo em que classificou aquelas que foram despidas de crédito, de valor, de prestígio e, portanto, de direito de reprodução.

A diferença colonial trata da construção de trajetos geo-históricos de clivagem discursiva que atijolaram os valores eurocêntricos e impuseram aos não europeus um lugar marginal na história humana. Local em que as falas das vidas subalternizadas são desprestigiadas, reticentes, lacônicas e tratadas como se primitivas fossem. Tratase, nesse sentido, da elaboração de circuitos, concretos e simbólicos que, desde a colonização, são utilizados para o trânsito de saberes validados socialmente, em que as linguagens e as gnoses periféricas não possuem legitimidade (ALCOFF, 2016).

Assim sendo, a colonização e a modernidade com ela nascida implicaram em inúmeros processos de dominação que concretizaram ao longo do tempo os fundamentos discursivos da produção de identidades que foram segmentadas em uma estrutura vertical, tudo isso promovido pela ideia biológica de raça que tornou as diferenças em inimigas das sociedades modernas (QUIJANO, 2009). Não custa com isso pensar que a escravidão, que longamente decorreu no Brasil, agindo pelo princípio colonial de negar as narrativas emanadas das diferenças, orquestrou uma sofisticada rede de anulamento e invisibilização das narrativas subalternizadas que resilientemente ainda perdura. Com o apagamento social da presença física e simbólica das diferenças dentro da literatura, das ciências, da filosofia, dos espaços de produção das linguagens, da lei e da justiça, das artes, da política, enfim, das zonas de prestígio e poder social, tudo foi convertido a uma única linguagem, a colonial, e 
por consequência as instituições, os pensamentos, as pessoas, os saberes e as condutas foram transformados em polissemia de branquitude.

Conforme Dussel(1992), a colonização foi um verdadeiro espetáculo de encobrimento do Outro. $O$ indígena e $\mathrm{o}$ africano se tornaram pelas narrativas do europeu sujeitos desprovidos de complexidade, de sabedoria, de cultura, de política, de filosofia e espiritualidade. O discurso que foi globalizado era aquele que traduzia o não europeu como vidas inferiores, objetificadas e animalizadas (CÉSAIRE, 1978). Com sua humanidade destituída, sua identidade alocada em instâncias menores que a da branquitude,os marcadores das diferenças se tornaram em marcadores da desigualdade. Assim, o Outro foi convertido em uma espécie primitiva e tudo que dele derivava refletia, nessa lógica, o atraso humano. Nesse contexto, a diferença colonial fluiu por meio da noção supremacista dos europeus que, ao enunciar o Outro como um sujeito atrasado, ao mesmo tempo, autorreferenciavam-se como sujeitos de desenvolvimento, astúcia e sabedoria. Essa dinâmica de assimetrias das gnoses das diferenças sustentou a artilharia de negação das histórias locais que foram acidamente corroídas pela pretensa noção de superioridade e desenvolvimento que os povos europeus consideravam possuir.

Dessa forma, a negação da diferença dialoga intimamente com a lógica maniqueísta colonial que dividiu o mundo em duas zonas distintas: as das raças superiores (colonizadores) $\mathrm{x}$ as inferiores (colonizados). Esse pensamento dicotômico nutriu o senso de dever europeu de proteger as raças anunciadas como superiores, na medida em que entendiam necessário promover o banimento das raças anunciadas como inferiores e transformadas em inimigas da sociedade (QUIJANO, 2005).

Como inimigos os afrodescendentes e ameríndios estavam sujeitos à morte, uma vez que:

a morte do outro não é simplesmente a minha vida, na medida em que seria minha segurança pessoal; a morte do outro, a morte da raça ruim, da raça inferior (ou do degenerado ou do anormal), é o que vai deixar a vida em geral mais sadia; e mais pura (FOUCAULT, 2005, p. 305).

É notório que essa morte não é apenas física, é também simbólica e cultural. A morte do corpo é a consumação final de um processo lento e impiedoso que impõe às vidas negras o suplício diário do medo e desespero desencadeados por políticas mortíferas utilizadas pelo Estado ou por ele chanceladas a terceiros para promoção do banimento das diferenças (MBEMBE, 2016). Para tanto, a erradicação da alteridade 
não europeia,convertida em inimiga da branquitude, pode ser processada não apenas pelo assassinato em massa dos corpos afrodescendentes e ameríndios, mas no sucumbimento de tudo que dele deriva, suas memórias ancestrais, sua justiça, suas políticas, estéticas, espiritualidades e cosmologias variadas, enfim, nada deve restar em pé após a ardil artimanha da branquitude em negar o que a ela não reflete(NASCIMENTO, 1978).

Banidos dos circuitos acadêmicos, dos espaços políticos, das gerências empresariais e sendo constantemente tensionados às margens das sociedades, as memórias do povo ameríndio e negro foram varridas do imaginário coletivo das sociedades modernas, restando tão somente os discursos depreciativos produzidos pela branquitude hegemônica. Giselle Beiguelman, em Memória da amnésia: políticas do esquecimento, discute os processos intencionais que no Brasil promovem o memoricídio daquilo que fora determinado pelos interesses hegemônicos a ser considerado como dispensável e desprezível ao imaginário e história nacional:

\begin{abstract}
A história do Brasil traz tanto o extermínio da memória como o apagamento do outro, ambos os apagamentos inscritos nas suas páginas desde os primórdios da colonização. A catequese foi seu gesto inaugural, impondo a incorporação forçada à cultura católica dominante. E como não lembrar que a escravização de negrosafricanos começava, em teoria, por um ritual de esquecimento? Ainda que na prática não tenha se efetivado, como atestam as váriasrebeliões pela liberdade, pretendia-sedesvincular osescravizados de seu passado. Assim, conta-se que, antes de embarcar para o Brasil, sempre à noite, para que não pudessem memorizar o caminho, os escravizados eram obrigados a dar voltas em torno de uma árvore para que esquecessem de suas raízes: sua terra, sua identidade, as formas dos lugares (BEIGUELMAN, 2019).
\end{abstract}

Embora Beiguelman considere o apagamento das memórias uma coisa diferente do apagamento do Outro, entendo de modo diferente, já que julgo o extermínio das memórias de um povo ser por si mesmo o próprio apagamento desse povo, uma vez que a retirada da presença de certos grupos minoritários dos anais da história impõe à ancestralidade, bem como a seus descendentes, o enfraquecimento de suas identidades e consciência social, potencializando o desaparecimento simbólico, psíquico e cosmológico da alteridade.

Ainda conforme Beiguelman, a arte do apagamento de memórias é uma atividade que, no Brasil, é recorrente desde a colonização, em outras palavras: impor o esquecimento é uma prática já muito bem sedimentada no país e foi determinada por grupos que ocuparam e ocupam as tradicionais posições de privilégios. As técnicas de erradicação das memórias, embora tenham atualmente roupagens diferentes, ainda conservam os mesmos sentidos: anular o Outro inferiorizado 
desprestigiando tudo que dele emana e não atestando sua importância para a formação nacional. Por exemplo, não instituir espaços públicos de reconhecimento das atrocidades perpetradas pela branquitude colonial ou espaços que contemplem com nobre apreço a estética e cultura do povo negro, como também pela promoção de apologias aos discursos colonizadores por meio de honrarias aos algozes dos povos pretos e indígenas. Para tanto, a produção do apagamento das memórias negras consiste em duas matrizes de silenciamento que operam: uma pela contenção de ambientes memoriais do holocausto negro e indígena ou da resistência, sabedoria e lutas desses povos; e outra pelo desenvolvimento de mitos e ideologias coloniais que fustigam a realidade gritante das desigualdades promovidas pelo racismo brasileiro.

O mito da democracia racial é uma dessas anedotas da burguesia de origem escravagista e colonial que, ao desconsiderar a continuada realidade de pobreza e marginalização imposta aos pretos e pretas após a abolição da escravidão no país, sustenta ativamente a ideia da culpabilização da vítima por suas misérias(DOMINGUES, 2005). A lógica da autorresponsabilidade pelo alijamento de direitos sociais das populações negras, embora seja estapafúrdia, foi facilmente disseminada entre as mais variadas classes sociais brasileiras, uma vez que a branquitude deste país sempre conservou em suas mãos os dispositivos tradicionais de fala e de prestígio de fala dentro da sociedade. Com isso, não Ihes era difícil incutir no imaginário brasileiro as falácias coloniais, já que suas histórias facilmente transitavam pelos trajetos epistemológicos e possuíam caráter de verdade absoluta. Com o tempo, à medida que crescem os movimentos de afirmação da negritude no Brasil, a noção de democracia racial passa a ser recorrentemente contestada. Contudo, os efeitos deletérios dessa concepção branca sobre as desigualdades raciais já estavam muito bem estabelecidos e já floresciam em outros igualmente nefastos rebentos, como a noção de meritocracia.

Não é por outra razão que as mais altas chefias do executivo nacional, o presidente e o vice-presidente da República, Jair Bolsonaro e Hamilton Mourão, respectivamente, negaram a existência do racismo no Brasil ao se referirem à morte brutal de João Alberto, cidadão negro que foi executado por seguranças do supermercado Carrefour na cidade de Porto Alegre/RS (FOLHA DE SÃO PAULO, 2020). Os discursos de Bolsonaro e Mourão não se tratam de descuido ou equívoco de quem desconhece a história brasileira, mas estão inscritos em uma ordem tradicional que secularmente vem operando para a negação dos intensos e extensivos 
processos de produção das muitas mortes às quais estão sujeitas as populações negras do país. Trata-se, portanto, de políticas do esquecimento engendradas pela colonialidade estrutural, que força, ao longo da história desta nação, ao sucumbimento dos afrodescendentes brasileiros.

As falas do presidente e de seu vice exploram as memórias do sujeito colonizador,e não as dos negros colonizados. A negação do racismo é a negação de todas as memórias de sofrimento que se descortinam desde as plantações latifundiárias coloniais até os dias de hoje. Os discursos, vindo dessas autoridades, não tratam apenas do esquecimento promovido pela diferença colonial, mas são manifestações políticas, uma vez que a desconsideração dessa realidade implica na não produção de políticas públicas para enfrentamento do racismo, permitindo, com isso, que milhares de vidas tombem ao peso da discriminação racial. Nesse sentido, os discursos das lideranças políticas do executivo nacional transportam o apagamento das memórias da escravidão e de suas feridas ainda abertas no Brasil, ao mesmo tempo em que implantam histórias contraproducentes aos fatos. A postura da atual cúpula do executivo diz respeito ao memoricídio das imagens, discursos e saberes dos povos colonizados, negando suas realidades de morte e possibilitando a (re)produção de fantasias de outra realidade que só tende a beneficiar os grupos hegemônicos.

Embora não exista uma conceituação precisa a respeito do termo memoricídio, aqui utilizo o entendimento de Fernando Báez(2010) que o define como os processos de eliminação intencional do patrimônio tangível ou intangível que representam a luta e resistência dos povos colonizados (BÁEZ, 2010). Portanto, o memoricídio é uma prática incursa nas vontades e projetos coloniais que se recusa a incorporar os bens dos povos colonizados nos espaços memoriais das sociedades. Enquanto prática efetiva de assassinato de memórias dos povos subalternizados, é uma realidade possível graças à ampla e capilarizada rede de dispositivos e tecnologias que atuam para o esquecimento de memórias sociais. Sua execução depende, desse modo, das assimetrias impostas pelas relações de poder que garantem a pessoas e instituições o poder de determinar que memórias sobreviverão, bem como aquelas que serão esquecidas. Portanto, o memoricídio é uma política do esquecimento executada pelo poder colonial contra os povos colonizados.

Essas políticas do memoricídio se fortalecem e se retroalimentam, como já mencionado, de processos discursivos e ideológicos como, por exemplo, a ideia de democracia racial, que faz com que as políticas da morte de memórias operem em 
fluxo constante de retomada das narrativas coloniais, reativando, sempre que possível, as linguagens do colonizador que asfixiam os discursos negros. Ou seja, essas políticas, ao reafirmarem as histórias globalizadas pela diferença colonial, simultaneamente retiram do cenário memorial as histórias que do outro lado da diferença hegemônica experimentam os horrores da desumanidade a eles imposta impedindo duramente que outras narrativas sejam faladas e escutadas nos espaços sociais. Logo, as políticas do esquecimento manipulam sincronamente os objetos, pessoas, saberes, fatos, feridas e histórias que serão suscitadas recorrentemente e transferidas de geração para geração como um legado, bem como enunciam os artefatos do esquecimento àqueles que serão desprezados, desvalorizados e fadados às zonas sombrias das memórias rejeitadas e não pertencidas (FOUCAULT, 2002).

Exemplos de políticas de esquecimento são os decadentes investimentos públicos em museus, arquivos e espaços de artes. Em recente artigo publicado por Simone PondéVassallo e Luz Stella Rodríguez Cácere, em que discutem as dificuldades de implantação na cidade do Rio de Janeiro do Museu da Escravidão e da Liberdade (MEL), destacam que:

o projeto do MEL encontra-se no cerne de tensões políticas muito mais amplas, daí a grande dificuldade da sua implementação. Os conflitos que o perpassam são reflexos de embates políticos travados numa esfera mais abrangente, o que deixa o projeto do museu tão fragilizado que corre o risco de sucumbir antes mesmo de vir à tona. Por um lado, o MEL atualiza as tensões entre as memóriasda escravidão e da herança africana e traz à tona os fantasmas gerados pelas aviltantes representações públicas dos escravizados, gerando resistência por parte significativa dos ativistas negros e contribuindo para oisolamento da secretária de Cultura. Por outro, o museuestariarelacionado a um projeto de nação que reconhece a importância dos africanos e seus descendentes na sua construção e a sua dívida para com os mesmos, mas que parece ser contrário aos interesses dos setores que assumiram o poder tanto no município quanto no governo federal. Por isso, ele não tem mais o suporte do Estado ou ao menos dos órgãos centrais à sua realização. Assim, enquanto o governo delega a sua responsabilidade, o projeto do MEL se enfraquece, a secretária de Cultura se isola e a "verdade" do museu é silenciada antes mesmo de ser formulada. O projeto do MEL gira em círculos, cada vez mais agonizante (VASSALLO; CÁCERES, 2019, pp. 76-77)

O que se descortina com a realidade do MEL é a disputa de matrizes ideológicas existentes na sociedade brasileira. De um lado, ao desrracializar a sociedade por meio do ensaio elogioso da miscigenação, fortalece a crença da democracia racial que historicamente oculta as desigualdades raciais no país. De outro está a noção de que a memória negra e seu reconhecimento, além de afirmarem a importância dessas pessoas na formação da sociedade brasileira, colaboram para o fortalecimento do movimento afrodescendente na luta por direitos de equidade. Nesse 
embate, o que se presencia atualmente é o Estado cada vez mais alocado no lado da resistência branca, patriarcal e colonial, utilizando ainda todas as prerrogativas que the são conferidas para auferir êxito na interdição da recuperação, manutenção e disseminação das memórias negras.

Outro modo político de apagamento das memórias está na negação ao direito de fala da população negra organizado por uma robusta engenharia de transmutação de sua fala em anedota e do cerceamento do trânsito de pessoas negras em ambientes de ecoamento vocal. A tão conhecida imagem de Anastácia, uma escrava amordaçada, reflete muito bem a cultura escravagista de silenciamento das pessoas pretas, em especial as mulheres, que longamente ocupam nesse sistema os limites mais inferiores ao direito de fala e ao prestígio de fala.

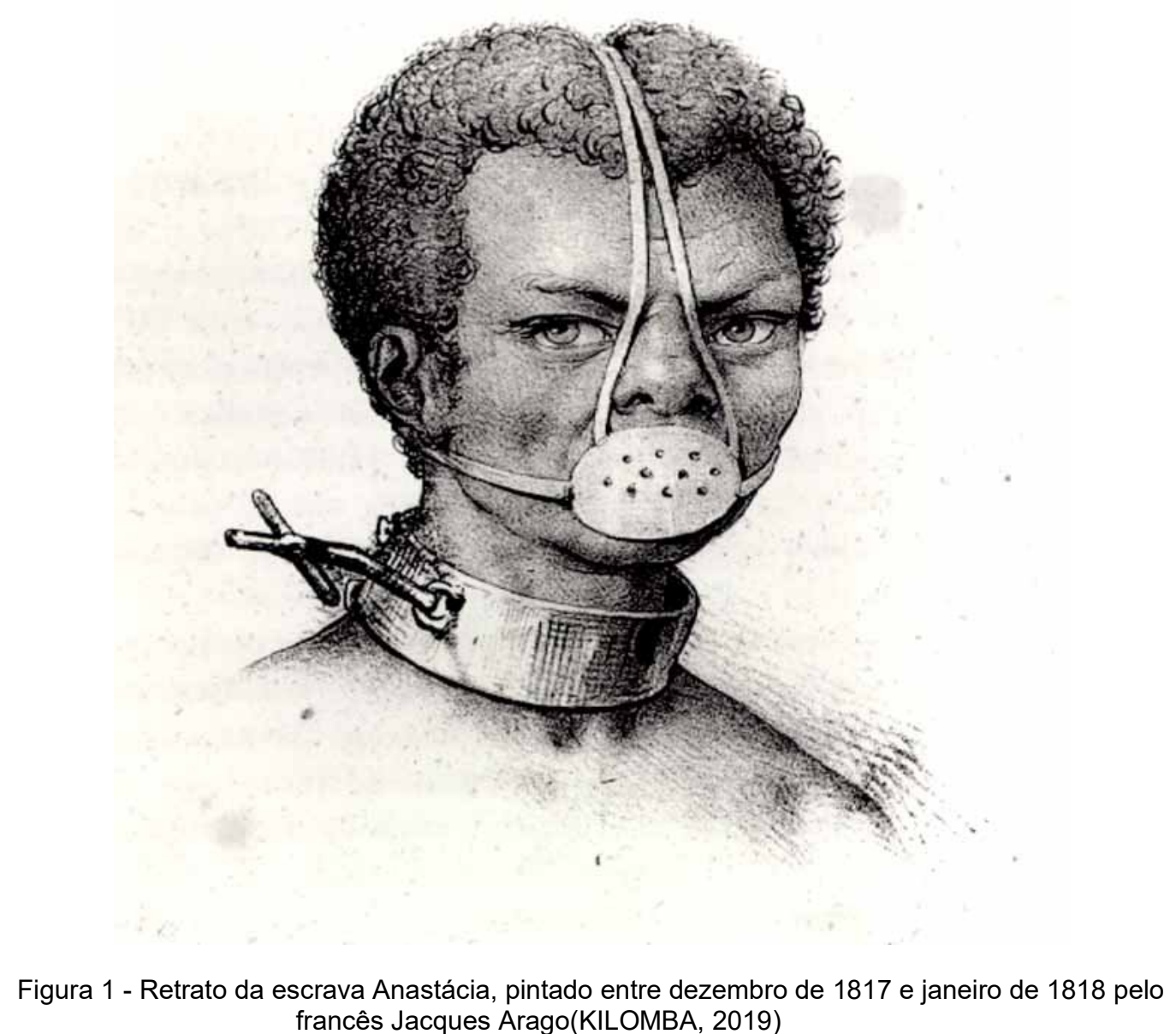
francês Jacques Arago(KILOMBA, 2019)

A máscara imposta a Anastácia é a reprimenda que impõe o segredo, que inibe a verdade, que silencia o discurso que denuncia. Contudo, a própria mordaça acusa a 
insegurança da branquitude com aquilo que pode ser dito pelas vidas caladas pela truculência colonial (KILOMBA, 2019). A imposição do silêncio não trata somente do poder de globalizar as narrativas que são denotadas como universais, mas diz respeito também aos limites, às fraquezas, às inseguranças do sujeito colonizador que não é capaz de sobreviver em contextos da verdade, necessitando ele mesmo construir suas verdades e sustentar-se em sua própria fantasia (DUSSEL, 2005).

Anastásia é o símbolo ancestral da violência colonial que calou o outro lado da diferença colonial, que ocultou as vozes que, mais do que o grito de dor, também emanavam a contestação a partir de suas redes de saberes que denunciavam o autorreferenciamento da branquitude que impunha ao mundo, pela espada e pelo capital, normas de vida que transcenderam os limites do continente europeu e foram definidas como sabres universais. Essas vozes de resistência garantiram que memórias sobrevivessem e superassem o tempo e alcançassem a atualidade. Assim, as vozes que ocupam as ruas e gritam que vidas negras importam são vozes ancestrais que resistem à supremacia racial a que estamos sujeitos e não permitem esquecer que a dor de hoje emana da ferida que sempre esteve aberta e que foi provocada pela colonização e capitalização dos povos do Sul Global. Vozes como as de Aqualtune, Zumbi dos Palmares, Dandara, Tereza de Benguela, Maria Firmina dos Reis, André Rebouças, Estêvão Silva, Luís Gonzaga Pinto da Gama, Luíza Mahin, José do Patrocínio, Carolina de Jesus, Abdias do Nascimento, Lima Barreto, Grande Otelo, Enedina Alves Marques, Sônia Guimarães, Marielle Franco, entre outras, somam-se a vozes de milhares de anônimas e anônimos para a conservação da jornada existencial, política, filosófica e social da negritude no Brasil.

O fato é que, embora a engenharia das políticas do memoricídio haja diuturnamente para a produção do esquecimento das memórias, saberes e culturas afrodescendentes, jamais a negritude latino-americana compartilhou dolosamente essas estruturas. Pelo contrário, suas vidas, suas artes, seus saberes e histórias transportaram para além do tempo e do espaço as riquezas e a dor de ser negra e negro neste país. A resistência veio por meio do aquilombamento e pela penetração determinada nos espaços políticos, artísticos e científicos hegemonicamente brancos, cisheterossexuais, masculinos e burgueses.

Como destaca Mignolo, a resistência não deve vir de outros campos senão das margens construídas pelas desigualdades impostas pela colonização, pois é das histórias ocultizadas, das experiências fustigadas, do locusfraturado que há o 
conhecimento capaz de questionar os lugares hegemônicos ocupados historicamente pela branquitude eurocêntrica (MIGNOLO, 2003). Assim, ecoar as memórias negras que foram tangenciadas ao esquecimento nos exige ruptura incisiva e definitiva com os modelos de saber, ser e fazer europeu e nos afirmar nas vozes do Sul Global (DUSSEL, 2012), reconhecendo que há em nossa terra e nossa gente uma potente filosofia capaz de nos libertar das amarras coloniais que ainda hoje nos amordaçam.

\section{Lembrar é preciso}

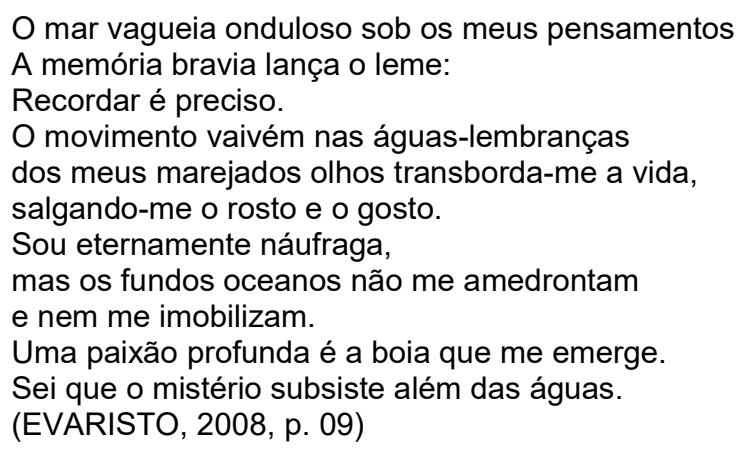

Conforme Souza (2019), o poema de Evaristo recupera de águas em que ficaram perdidas as duras lembranças dos navios negreiros, das tumbas que rasgavam o Atlântico e que agora vêm à mente para a reconstrução da liberdade. Para tanto, é nesse sentido que a eu lírica pode ser "eternamente náufraga", já "que os fundos oceanos não [a] amedrotam e nem [a] imobilizam" mais.

$\mathrm{Na}$ poesia de Conceição Evaristo, há um convite: é preciso recuperar as memórias perdidas pelos apagamentos executados pela colonização. Essas memórias, embora assoladas pela dor, nutrem-nos de coragem e força, para que se faça a implosão das heranças coloniais que impetram diuturnamente o mal racial que, hoje, talvez mate mais do que antes. Recuperar as memórias é o processo em que se permite vir à tona uma ferida nunca tratada, que sempre dói, que infecta a outros e tantas vezes sangra(KILOMBA, 2019). É assumir coletivamente que o desenvolvimento deste país foi feito por vidas negras que por mais de trezentos anos, enquanto trabalhavam, eram escravizadas e torturadas. É admitir que mesmo depois do fim da escravidão uma larga quantidade de leis buscou empobrecer, criminalizar e encarcerar a população negra, ou seja, recuperar memórias e transcender a limitada noção de herança negra restrita ao samba, pratos típicos e esportes, bem como reconhecer antes de tudo que nossas primeiras e longas lembranças nesse continente foram as da dor, morte e negação. 
A recuperação dessas memórias não está a serviço apenas do povo afrolatinoamericano, mas de toda pessoa afetada pelas toxinas coloniais, devolvendo também aos corações que foram dessensibilizados pelas tiranias normativas da colonização o direito de novamente amar e, por meio desse direito, recuperarem a humanidade perdida. Ou seja, as memórias afrodescendentes não restituem apenas a dignidade e o pertencimento dos povos negros, mas também possibilitam ao colonizador sua libertação. Conforme Césaire(1978), o colonialismo retirou do colonizador sua capacidade de amar, de sensibilizar-se, de ter compaixão pelas vidas não europeias, fez daquele que colonizava um animal embrutecido, pois somente assim poderia impor ao Outro o mal em toda sua potência de aniquilamento. Libertar a pessoa negra do silêncio, do esquecimento, da morte simbólica e concreta também liberta a pessoa branca (FANON, 2008). Trata-se de uma libertação dialógica engendrada pela eterna corrente da cumplicidade humana que une todos e todas. Não há mistérios ou segredos. Retomar as memórias periféricas permite aos centros tradicionais reconfigurar percursos e corrigir trajetórias salvando todas e todos da autodestruição (CARVALHO, 2018).

Em 2020, entre pandemia, confinamento, crises diplomáticas, aprofundamento do fracasso capitalista em promover o desenvolvimento e sustento das nações, o mundo viu disseminar por suas ruas vozes anunciando que vidas negras importam. $O$ grande movimento em prol dos direitos das pessoas negras desencadeado com a morte de George Floyd em maio deste ano é o grito de milhares que permanentemente são ameaçados pelo projeto político de extermínio das diferenças que, no Brasil, Abdias do Nascimento já denunciava no final da década de 1970. Esse movimento questiona em muitos sentidos a posição hegemônica da branquitude pondo em xeque o discurso colonial apologético às memórias escravagistas que se encontram dispersas nos territórios urbanos por meio de distintos monumentos, nomes de ruas, de praças, prédios públicos e outras tantas reminiscências que prestam perseverantemente o enaltecimento à tirania colonial, ao mesmo tempo em que destituem da história fatos e personalidades oriundas das margens. Tais recursos tornam as comunidades negras despatriadas em suas próprias cidades, desalojadas de seus territórios, uma vez que não há nada que possa, dentro da cartografia simbólica das cidades,sugerir a colaboração dessas pessoas na edificação das sociedades atuais. A falta de elementos identificadores é, portanto, uma forma de desterritorialização das populações negras de suas cidades, já que por meio desses 
processos põe para fora dos espaços citadinos, simbólica e materialmente, a negritude brasileira.

A desterritorialização preta não é processo recente. Nas Américas suas raízes estão na forçosa diáspora africana do século XVI, perpassando pelo plantation colonial, pela Lei de Terras de 1850, pela escassez de expedientes para pessoas negras nos perímetros urbanos, que culminou com o tensionamento desses grupos às periferias que tardiamente, enquanto territórios marginalizados e desassistidos pelo Estado, foram criminalizados e anuídos como locais de aglutinamento de desigualdades. A desterritorialização negra tornou os espaços sociais das cidades brasileiras em verdadeiros espelhos da colonialidade, refletindo, de inúmeros modos, o pensamento e poder colonial. Desse modo, tais processos acabaram por promover profundo apagamento das memórias e identidades negras nos contextos urbanos, varrendo completamente de determinados territórios geográficos do país a presença afro-brasileira (SOUZA, 2012).

A exemplo da cultura da desterritorilização urbana como memoricídio, tomemos o caso da cidade de São Paulo que, em 2017, pela mão do então prefeito, João Dória, mergulhou a cidade em um mar de cinza ao promover o apagamento de centenas de artes gráficas que, espalhadas pelos muros, viadutos e prédios de São Paulo, reivindicavam espaços de pertencimento e se faziam memórias dos coletivos minoritários, em especial o da população negra. O governo da cidade paulista chamou aquela arte urbana de vandalismo (EL PAís, 2017), em uma clara ação para subverter as imagens e práticas culturais de predominância negra em crime e prática desprestigiosa. O apagamento dos grafites urbanos é, inequivocamente, uma prática de memoricídio, já que em territórios de brancura dominante o "grafite predominante na cidade toda é uma forma visual em que as representações da raça na paisagem urbana, na selva de concreto, são reapropriadas, em que as representações dominantes da branquitude em uma cidade negra são contestadas" (FINN, 2010, p. 93). O apagamento dessas artes não somente tiram de circulação as expressões e protestos negros, mas também as criminaliza. Há com isso uma pressão que segrega para as periferias o grafite, fazendo com que haja um evidente muro simbólico que também pela arte divide notoriamente o centro das margens.

Enquanto presença nos espaços públicos, a arte de rua exposta pelo grafite incomoda os grupos hegemônicos porque expressa, sobretudo, as desigualdades sociais que crescem nesses locais. Portanto, a arte das periferias não se vincula 
estritamente à noção de estética tradicionalmente validada, possui muito mais comprometimento com os sentidos que se encontram arraigados nos movimentos de resistência que agem pela ressignificação dos espaços públicos e do sentimento de pertencimento das cidades(FERREIRA; KOPANAKI, 2015). Retirar os grafites das cidades é uma forma de impor o silêncio às vozes periféricas que criativamente produzem resistência aos dispositivos e tecnologias de poder que atuam como políticas de invisibilização e esquecimento dos grupos subalternizados, ou seja, tratase da velha mordaça de Anastácia.

Outra forma de promover o declínio das narrativas afrodescendentes é no cerceamento ao direito de fala, controlando-se os meios em que preferencialmente transitam as linguagens creditadas de prestígio e reconhecimento. Em uma grande pesquisa realizada pelo Grupo de Estudos em Literatura Brasileira Contemporânea, coletivo de pesquisadores e pesquisadoras vinculadas à Universidade de Brasília (UNB), fez-se uma varredura em livros publicados por grandes editoras do país, entre 1965 e 2014, e verificou-se que 90\% das obras publicadas por essas editoras foram de homens brancos e $60 \%$ das histórias protagonizadas por homens, $80 \%$ deles brancos, e $90 \%$ por heterossexuais, e apenas $2 \%$ do grande acervo publicado era de autores negros e menos ainda por mulheres (O POVO, 2017). Os resultados da pesquisa apontam para o silenciamento da população negra nos espaços editoriais, em especial da mulher negra. Ao restringir a penetração dessas e desses autores na escrita literária, os grupos hegemônicos anunciam que histórias devem ser lidas, quais não podem ser faladas ou escutadas e forjam em grande medida a construção da identidade negra circunscrita ao narcisismo da branquitude brasileira. Para Lima (2009), o cânone literário do Brasil não apenas silenciou os escritos negros ao longo da história literária nacional, como também em vários momentos da história do país agiu para adepreciação e dominação das pessoas negras. A obstrução do acesso à leitura e escrita não se trata, pois, apenas do banimento da negritude dos espaços culturais do saber, mas de converter os próprios espaços de produção de conhecimento em engrenagens de dominação e expropriação das identidades afrobrasileiras. Retirar a negritude dos circuitos de escrita significa impor as suas histórias o esquecimento e esfacelar as narrativas vertidas das margens na tentativa de diminuir a consciência africana, que ainda impera para a branquitude nacional como uma ameaça. 
Em contrapartida, autores como Silvio Almeida e autoras como Djamila Ribeiro, Maya Angelou e Angela Davis figuram atualmente entre os livros mais lidos no Brasil (CASA 1, 2020), demonstrando a consistência da potência dessas personalidades ao mesmo tempo em que derretem as mesquinhas ilusões da normatividade branca e colonial. Esses dados contestam por si só o locusfraturado para onde foi arremetida a sabedoria afro-brasileira e implica no testemunho histórico de que a negritude desse país, apesar de todos os pesares, jamais quedou em silêncio. Os autores e autoras negras liquidamente vêm se infiltrando nos espaços hegemônicos por meio de rachaduras produzidas pela histórica luta de seus ancestrais. O fato é que o que se percebe, ao menos nas últimas duas décadas, é que a escrita negra que tem alçado voos cada vez maiores é uma repercussão sólida da organização negra para o enfrentamento da interdição ao pensamento afrodescendente imposto pelas estruturas raciais. O surgimento de editoras independentes para publicação de pensadores e pensadoras negras é uma das formas de resistência encontrada para que essa população possa falar de si e do seu mundo, bem como as redes sociais que têm alcançado um vasto público por meio de postagens e lives voltadas às experiências negras.

Percebe-se, ainda, que a autoria negra tem produzido um conteúdo expressivo que dá destaque às faces ocultas da discriminação racial, amplamente negadas pelo discurso colonial que articulou as muitas tecnologias de fala das quais dispunha para tecer o manto da modernidade que cuidou em ocultar as violências do passado e presente produzidas pela colonização da América Latina (MIGNOLO, 2003). Autores como Carolina Maria de Jesus, Eliana Alves Cruz, Conceição Evaristo, Maria Firmino dos Reis, Mel Adún, Urânia Munzanzu, Jeferson Tenório, entre outras e outros já citados aqui, falam em suas obras, artísticas ou científicas, das desigualdades que foram produzidas e conectadas pelo racismo colonial, sendo comum no atual momento da escrita negra no Brasil a apropriação daquilo que vem sendo discutido dentro da academia como Lugar de Fala. Esse termo, embora venha sendo cada vez mais utilizado, não possui uma etimologia e epistemologia própria, surge dos estudos sociais a partir de pesquisadoras e pesquisadores afro-americanos que começaram a utilizar o termo para evidenciar os pilares que sustentam os olhares, bem como para a enunciação das zonas fronteiriças da linguagem. No Brasil, o termo ganhou notoriedade a partir da publicação, em 2017, do livro da filósofa Djamila Ribeiro intitulado $O$ que é lugar de fala. A noção de lugar de fala tem relações diretas com o direito de produção de memórias ancestrais e culturais de um povo, da mesma 
maneira que as políticas de esquecimento a que estão sujeitas as linguagens periféricas que anunciam as histórias locais de modo desarrazoado. Segundo Djamila Ribeiro, o lugar de fala surge em virtude das abissais desigualdades impostas às populações marginalizadas que por:

\begin{abstract}
não poder acessar certos espaços, acarreta em não se ter produções e epistemologias desses grupos nesses espaços; não poder estar de forma justa nas universidades, meios de comunicação, política institucional, por exemplo, impossibilita que as vozes dos indivíduos desses grupos sejam catalogadas, ouvidas, inclusive, até de quem tem mais acesso à internet. $O$ falar não se restringe ao ato de emitir palavras, mas de poder existir. Pensamos lugar de fala como refutar a historiografia tradicional e a hierarquização de saberes consequente da hierarquia social. Quando falamos de direito à existência digna, à voz, estamos falando de locus social, de como esse lugar imposto dificulta a possibilidade de transcendência. Absolutamente não tem a ver com uma visão essencialista de que somente o negro pode falar sobre racismo, por exemplo(RIBEIRO, 2017).
\end{abstract}

Ou seja, o lugar de fala é, ao mesmo tempo, resistência à imposição do silêncio em que é diálogo com as diferenças. Nesse sentido, lugar de fala emerge como uma ação de desocultamento dos sofrimentos perpetuados pelo escravagismo colonial, sendo uma evidente forma de superação da diferença colonial que cria constantemente condições e meios dialógicos em que uma enunciação fraturada sobre o Outro é mobilizada pela negação dessas pessoas como seres humanos (MIGNOLO, 2003). Contudo, as mesmas dicotomias produzem possibilidades, nascidas no locussubalternizado, de transcendência da diferença colonial. Ou seja, o lugar de fala descolonializa estruturas e sistemas à medida que gera novos terrenos epistemológicos nascidos pelas perspectivas de subalternidade, onde o pensamento de fronteira é exercitado (MIGNOLO, 2003).

Nesse contexto, a escrita negra preserva memórias acessando feridas e discutindo não o outro lado da margem, mas seu próprio local, pois encontra nesse lugar formas criativas para dialogar com os grupos hegemônicos, rompendo com as estruturas do silêncio e lançando ao mundo os sons e imagens que acessam o passado, o presente e as possibilidades de futuro das populações negras. Desse lugar enuncia críticas contra os projetos estéticos, filosóficos, artísticos, científicos e culturais normatizados pelos padrões eurocêntricos que desde final do século XV se estendem sobre nós. Na prática, o que vemos nas memórias escritas que vêm sendo produzidas por autores e autoras negras de nosso tempo é uma textualidade centrada nas vivências e dramas de tornar-se negro e negra na sociedade brasileira, perfilando os entraves e dilemas das relações sociais, acima de tudo étnico-raciais, estabelecidos pelo racismo (SANTIAGO, 2012). 
Ao falar sobre o lançamento de seu livro Beco de memórias, ao site Geledés, Conceição Evaristo diz:

\begin{abstract}
Eu tenho a impressão que aqui na França, o que eu conto com a PonciáVicêncio, e também em Becos da Memória, traz justamente a voz afro-brasileira, essa voz nascida de dentro, nascida da experiência, nascida da condição dos negros brasileiros. A França até conhece romances brasileiros que chegam até aqui, mas são sempreromances escritos de fora pra dentro. Eu tenho a impressão de que meus livros trazem esseoutrolugar, que é o lugar de fala de uma autoria negra brasileira (GELEDÉS, 2017).
\end{abstract}

O lugar de fala é, desse modo, o esteio da consciência que, entretecida na força da história de um povo, permite àquela pessoa que foi obrigada a repousar sua existência nos domínios do silêncio falar de suas experiências confrontando epistemologias e outros saberes conformados pelas posições hegemônicas em verdades universais. Para tanto, o lugar de fala hoje ocupado pela escrita negra nacional é marcado acentuadamente pela linguagem que recupera memórias secularmente negadas, traduzindo em diferentes arenas os olhares não enunciados pelo cânone literário e científico que obnubilou os saberes da negritude marginalizada.

Enfim, embora seja alta a envergadura das políticas do esquecimento no Brasil, que agem desde os campos discursivos do saber às várias cartografias urbanas, a resistência negra se coloca à altura na luta perene na defesa de suas memórias. A produção dessa resistência promovida no lugar de fala, no qual se sustentam os interlocutores da negritude nacional, possibilita a elaboração de novas possibilidades de diálogo com grupos dominantes no desenvolvimento de esteios mais diversos e equânimes.

\title{
Considerações finais
}

As histórias das vivências negras foram soterradas pelo outro lado da diferença colonial que, ao globalizar suas narrativas e projetos, negou a fala e apagou com ela as memórias do povo negro brasileiro. Pensando em discutir os processos de apagamento das memórias afro-brasileiras, este artigo se apropriou do conceito de memoricídio para problematizar o aniquilamento das vozes, símbolos e outros bens produzidos pela negritude do Brasil como uma política do esquecimento que se encontra em curso no projeto colonial de vencimento das diferenças para sua permanente exploração.

Discutiu-se, ainda, mesmo que brevemente, a resistência promovida pelos guardiões e guardiãs das memórias negras que a partir do lugar de fala demarcado 
pelas margens sociais que não quedam às forças opressivas da colonialidade vigente, sendo suas vozes a edificação de novas possibilidades dialógicas para superação da diferença colonial.

Por fim, o apagamento das memórias e identidades negras no Brasil é um projeto colonial muito bem consistente e altamente capilarizado que atua em diversas linhas por meio das políticas do esquecimento que agem para anular e silenciar a presença negra desde os espaços artísticos e do saber aos ambientes públicos e urbanos. Contudo, a resistência criativamente vem se apoderando de formas variadas, como a escrita em produção independente, a arte de rua e os ciberespaços, para falar, a partir de seu lugar, as dores e prazeres da experiência negra brasileira, construindo assim novas pontes para superação do racismo.

\section{Referências}

ALCOFF, L. M. Uma epistemologia para a próxima revolução. Revista Sociedade e Estado, v. 31, n. 01, p. 129-143, 2016.

ALESSI, G. A 'maré cinza' de Doria toma São Paulo e revolta grafiteiros e artistas: Prefeitura apaga grafites da av. 23 de Maio e diz, agora, que fará seleção de novos artistas Para especialista, declarar "guerra ao picho" é "tiro no pé" do novo prefeito da cidade. El País, São Paulo, 24 de jan. de 2017. Diponívelem:https://brasil.elpais.com/brasil/2017/01/24/politica/1485280199_418307.ht ml. Acesso em: 25 de nov. de 2020.

BÁEZ, F. A história da destruição cultural da América Latina: da conquista à globalização. Rio de Janeiro: Editora Nova Fronteira, 2010.

BEIGUELMAN, G. Memórias da amnésia: políticas do esquecimento. São Paulo: Edições Sesc, 2019.

BOIS, W. E. B. DU. As Almas da Gente Negra. Rio de Janeiro: Lacerda, 1999.

Dos 20 livros mais vendidos do país, sente são de autoria de pessoas negras. Casa 1 , São Paulo, 14 de jun. de 2020. Diponível em: https://www.casaum.org/dos-20-livrosmais-vendidos-do-pais-sete-sao-de-autoria-de-pessoas-negras/>. Acesso em: 27 de nov. de 2020.

CARNEIRO, S. Racismo, sexismo e desigualdade no Brasil. São Paulo: Selo Negro, 2011.

CARVALHO, A. S. DE. A alienação em Frantz Fanon: da consciência a descolonização. Kwanissa, n. 02, p. 20-34, 2018.

CÉSAIRE, A. Discurso sobre o colonialismo. Lisboa: Livraria Sá da Costa Editora., 1978.

COLETTA, R. D.; TEIXEIRA, M.; ROCHA, M. No Brasil não existe racismo, é coisa que querem importar, diz Mourão sobre morte de Beto Freitas em mercado. Folha de 
São Paulo, São Paulo, 20 de nov. 2020. Diponível em: https://www1.folha.uol.com.br/cotidiano/2020/11/no-brasil-nao-existe-racismo-e-coisaque-querem-importar-diz-mourao-sobre-morte-de-beto-freitas-em-mercado.shtml. Acesso em: 25 de nov. de 2020.

COSTA, I. Pesquisa analisa o perfil dos autores brasileiros nos últimos 49 anos: Segundo dados da UNB, perfil dos autores brasileiros segue o mesmo padrão desde 1965 - com predominância de homens e brancos entre quem consegue publicar nas grandes editoras. O Povo, Brasília, 30 de nov. de 2017. Diponível em: https://www.opovo.com.br/jornal/vidaearte/2017/11/pesquisa-analisa-o-perfil-dosautores-brasileiros-nos-ultimos-49-anos.html. Acesso em: 25 de nov. de 2020.

Vice-presidente nega fator racial no espancamento de homem negro por seguranças do Carrefour de Porto Alegre

DOMINGUES, P. O mito da democracia racial e a mestiçagem no Brasil (1889-1930). Diálogos Latinoamericanos, n. 10, p. 117-131, 2005.

DUSSEL, E. 1492. O encobrimento do outro: a origem do mito a modernidade. São Paulo: Vozes, 1992.

DUSSEL, E. Europa, modernidade e eurocentrismo. In: A colonialidade do saber: eurocentrismo e ciências sociais. Perspectivas latino-americanas. Buenos Aires: CLACSO, ConsejoLatinoamericano de CienciasSociales, 2005. p. 22-34.

DUSSEL, E. Para um diálogo inter-filosófico, Sul-Sul. Revista do Instituto Superior de Filosofia Berthier, n. 41, p. 11-30, 2012.

EVARISTO, C. Poemas da recordação e outros movimentos. Belo Horizonte: Nandyala, 2008.

FANON, F. Pele negra, máscara brancas. Salvador: EDUFBA, 2008.

FERREIRA, M. L.; KOPANAKI, A. R. A cidade e a arte: um espaço de manifestação. Tempo da Ciência, v. 22, n. 44, p. 79-88, 2015.

FINN, J. Propaganda, grafite e as representações de uma cidade negra. ETD Educação Temática Digital, v. 11, n. 02, p. 75-101, 2010.

FOUCAULT, M. Arqueologia do saber. Rio de Janeiro: Forense Universitária, 2002.

FOUCAULT, M. Em defesa da sociedade. São Paulo: Martins Fontes, 2005.

FRANÇA, T. M. Um olhar sobre o conceito de memória discursiva de Michel Pêcheux. Interletras, v. 04, n. 22, p. 01-10, 2016.

JÚNIOR, J. Becos da Memória - A força da memória para pensar o passado e o presente. Geledés, São Paulo, 06 de jan. de 2019. Diponível em: https://www.geledes.org.br/becos-da-memoria-a-forca-da-memoria-para-pensar-opassado-e-o-presente/. Acesso em: 26 de nov. de 2020.

KILOMBA, G. Memórias da plantação: episódios de racismo cotidiano. Rio de Janeiro: COBOGÓ, 2019.

LIMA, C. B. DE. Literatura negra - uma outra história. Terra roxa e outras terras Revista de Estudos Literários, v. 17- A, p. 67-77, 2009. 
MBEMBE, A. Necropolítica: Biopoder, soberania, estado de exceção, política da morte. Arte \& Ensaios, v. 32, p. 123-151, 2016.

MIGNOLO, W. D. Histórias locais/projetos globais: colonialidade, saberes subalternos e pensamento liminar. Belo Horizonte: Editora UFMG, 2003.

MORRISON, T. Racismo e fascismo: O corpo escravizado e o corpo negro. São Paulo: Companhia das Letras, 2020.

NASCIMENTO, A. DO. O Genocídio do Negro Brasileiro: processo de um racismo mascarado. Rio de Janeiro: Paz e Terra, 1978.

PALMA, R. DA; TRUZZI, O. Renomear para Recomeçar: Lógicas Onomásticas no Pós-abolição. Dados, v. 61, n. 02, p. 311-340, 2018.

POLLAK, Michael. (1989). Memória, Esquecimento, Silêncio. Estudos Históricos, 2(3), 3-15, Rio de Janeiro.

QUIJANO, A. Colonialidade do poder, eurocentrismo e América Latina. In: LANDER, E. (Ed.). . A colonialidade do saber: eurocentrismo e ciências sociais. Perspectivas latino-americanas. Buenos Aires: ConsejoLatinoamericano de CienciasSociales, 2005. p. 107-130.

QUIJANO, A. Colonialidade do poder e classificação social. In: SANTOS, B. DE S.; MENESES, M. P. (Eds.). . Epistemologias do sul. Coimbra: Almediana, 2009. p. 73117.

RIBEIRO, D. O que é lugar de fala? Belo Horizonte: Letramento, 2017.

SANTIAGO, A. R. Vozes literárias de escritoras negras. Cruz das Almas: Editora UFRB, 2012.

SILVA, J. B. R. DA. Cazumba\&Cazumbá: história, narrativa e as "fronteiras identitárias" no recôncavo baiano (séculos XIX-XXI). Saeculum- Revista de História, v. 37, p. 59-78, 2017.

SOUZA, J. DE. Afrodescendência: identidade desvelada na memória, 2012.

SOUZA, R. A. DE. Memória rasto em poemas de Conceição Evaristo. Anuário de Literatura, v. 24, n. 01, p. 13-22, 2019.

VASSALLO, S. P.; CÁCERES, L. S. R. Conflitos, verdades e política no Museu da Escravidão e da Liberdade no Rio de Janeiro. Horizonte Antropológico, v. 25, n. 53, p. 47-80, 2019. 